\title{
O ACENTO VERBAL NO PORTUGUÊS BRASILEIRO: CARACTERIZAÇÃO MÉTRICA E GRAMÁTICA DE RESTRIÇÕES
}

\author{
Fernanda Alvarenga REZENDE (D) $\boldsymbol{X}$ \\ Universidade Federal de Uberlândia (UFU)
}

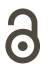

\section{OPEN ACCESS}

EDITADO POR

- Miguel Oliveira, Jr. (UFAL)

- René Almeida (UFS)

REVISADO POR

- Athany Gutierres (UFFS)

- Elisa Battisti (UFRGS)

\section{DATAS}

- Recebido: 25/06/2020

- Aceito: 03/02/2020

- Publicado: 20/12/2020

\section{COMO CITAR}

REZENDE, Fernanda Alvarenga (2020) $O$ acento verbal no Português

Brasileiro: caracterização métrica e gramática de restrições. Cadernos de Linguística, v. 1, n. 2, p. 01-20.

\section{RESUMO}

Neste estudo, pretendemos lançar novas luzes sobre as investigações, até então, realizadas acerca do padrão de acento dos verbos no português brasileiro (PB), associando o modelo de restrições da Teoria da Otimidade com os princípios fundamentais da Fonologia Métrica (HAYES, 1995). Propomos uma análise do acento verbal, incluindo os contrastes acentuais (ex.: "parte" e "parti") presentes nesta classe de palavras e que não aparecem nos trabalhos sobre o assunto. Com base na Teoria Métrica Paramétrica, de Hayes (1995), consideramos que três parâmetros são suficientes para captar os fatos referentes ao acento primário dos verbos no PB, quais sejam: a. Construção do pé: forme um troqueu silábico não-iterativo da direita para a esquerda. Pés degenerados são permitidos apenas na posição forte, quando o pé canônico não puder ser formado (proibição fraca); b. Extrametricidade: a desinência de plural na $1^{\text {a }}$ e $2^{\text {a }}$ pessoas do plural dos verbos dos tempos do imperfeito, do mais-que-perfeito e do futuro do pretérito do indicativo. Nos casos restantes, a consoante final com status de desinência, ou seja, $N$ ou $S$; c. Regra Final: à direita. Dentre os resultados que obtivemos, destacamos que a estrutura interna da sílaba não foi relevante para o acento verbal e, por essa razão, podemos afirmar que o peso silábico não importa para os verbos. A interação morfologia-fonologia, que se mostra evidente em cada tempo verbal, reforça a importância das restrições de alinhamento para a análise e reconhece a relevância das informações morfológicas para o acento dos verbos. 


\section{ABSTRACT}

In this study, we intend to shed new lights on the investigations proposed about the stress pattern of verbs in Brazilian Portuguese (BP), associating Optimality Theory constraints model with fundamental principles of Metrical Phonology (HAYES, 1995). We propose an analysis of the verbal stress, including the stress contrasts (for example: "parte" and "parti") present in this class of words and which do not appear in the works on the subject. Based on Parametric Metrical Theory (HAYES, 1995), we considered that three parameters are sufficient to capture the facts regarding the primary stress in the BP verbs, namely: a. Foot construction: form a non-iterative syllabic trochee from right to left. Degenerate feet are only allowed in the strong position, when the canonical foot cannot be formed (weak prohibition); b. Extrametricality: the plural ending in the 1st and 2nd person of the plural of the verbs of the imperfect, the more-than-perfect and the future of the past tense of the indicative. In the remaining cases, the final consonant with the ending status, that is, Nor $S$, c. Final Rule: on the right. Among the results we obtained, we highlight that the internal structure of the syllable was not relevant for the verb stress and, for this reason, we can affirm that the syllable weight does not matter for verbs. The morphology-phonology interaction, which is evident in each verb tense, reinforces the importance of alignment constraints for the analysis and recognizes the relevance of the morphological information for the verb stress.

PALAVRAS-CHAVE

Acento verbal; Português brasileiro; Fonologia Métrica; Teoria da Otimidade.

\section{KEYWORDS}

Verb Stress; Brazilian Portuguese; Metrical Phonology; Optimality Theory. 


\section{INTRODUÇÃO}

O objeto de análise deste trabalho é o acento dos verbos, mais especificamente, o acento primário verbal no português brasileiro (PB), com base na Fonologia Métrica, de Hayes (1995), e na Teoria da Otimidade (TO), de McCarthy e Prince (1993a, 1993b), Prince e Smolensky (1993) e Kager (1999), bem como nas propostas de Hyde (2001) acerca das restrições de alinhamento e de Magalhães $(2004,2010)$ sobre os não-verbos do português.

Um diferencial deste estudo é a análise do contraste acentual dos verbos no PB. Esse contraste aparece em verbos como "partira" (da primeira e da terceira pessoas do singular do pretérito mais-que-perfeito do indicativo), com acento paroxítono, e "partirá" (da terceira pessoa do singular do futuro do presente do indicativo), com acento oxítono. Em outras análises do sistema de acento do português pela TO, especialmente Lee $(1994,2007)$ e MassiniCagliari (2005), os contrastes acentuais não foram analisados, ainda que esses trabalhos tenham tratado do acento verbal.

Ademais, este estudo surgiu com o objetivo de construir uma análise teórica sobre o acento dos verbos no PB pautada nos princípios da Fonologia Métrica e no modelo de restrições da Teoria da Otimidade. Magalhães (2004, 2010) utilizou essas duas teorias em seus trabalhos acerca dos não-verbos, mas não tínhamos conhecimento de um que seguisse estas linhas teóricas, do modo como empreendemos, para a categoria verbal. Assim, pretendemos contribuir com as abordagens e descrições que tratam do acento no PB, especificamente, sobre os verbos.

Os objetivos específicos foram três, quais sejam: 1. Estabelecer uma interação entre a fonologia e a morfologia, por meio da atuação de restrições morfológicas e fonológicas; 2. Analisar os contrastes de acento nos verbos (ex.: entre "bati" e "bate" e entre "partira" e "partirá"), por mostrarem a relevância da informação morfológica para distinguir tempos verbais; e 3. Propor uma gramática de restrições para o sistema verbal do PB no que se refere ao acento.

As hipóteses que nortearam este estudo foram as seguintes: 1. O peso silábico não é relevante para os verbos (Lee, 2007), por isso, não importa qual é a estrutura interna da sílaba; 2. Se o peso silábico não importa e, considerando que a maioria das palavras do PB é paroxítona, o pé que rege o acento verbal é o troqueu silábico; 3. As informações morfológicas são fundamentais para o acento dos verbos; 4. As restrições de alinhamento são a base da hierarquia de restrições para captar o acento verbal; 5. O acento é previsível de acordo com o tempo verbal analisado.

Além das hipóteses, fizemos algumas perguntas, cujas respostas pretendíamos ter no fim desta pesquisa, quais sejam: 1. Na análise do acento verbal, qual é o papel das restrições morfológicas?; 2. O verbo será paroxítono se terminar em vogal e oxítono se terminar em consoante, como nos não-verbos?; 3. Os não-verbos acentuados na antepenúltima sílaba 
recebem um tratamento especial no que se refere ao acento, será que o mesmo acontece para os verbos proparoxítonos?; 4. Quanto às formas verbais dos tempos do futuro, como tratá-las: como sintéticas (simples) ou como analíticas (perifrásticas ou compostas)?; 5. Ao considerarmos o sistema de acento verbal, o português brasileiro é ou não uma língua sensível ao peso silábico?

Este artigo foi organizado em seis seções. Após esta introdução, fazemos uma breve apresentação da Fonologia Métrica, especificamente no modelo de Hayes (1995), e da Teoria da Otimidade (McCarthy e Prince, 1993a, 1993b; Prince e Smolensky, 1993; Kager, 1999; Hyde, 2001), que foram as bases teóricas utilizadas neste estudo. Na terceira seção, apresentamos a caracterização métrica do acento dos verbos no português brasileiro, bem como as restrições envolvidas na análise. Destinamos a quarta seção para a análise do acento verbal no PB e para a proposta de uma gramática de restrições. As considerações finais deste trabalho aparecem na quinta seção, seguidas pelas referências.

\section{FUNDAMENTAÇÃO TEÓRICA}

Segundo Hayes (1995, p. 1), "a teoria métrica do acento é um ramo da teoria da fonologia gerativa que lida com padrões de acento". Os pressupostos de Liberman (1975) e Liberman e Prince (1977) são a base do modelo proposto pelo autor, que considera o pé como o menor constituinte na estrutura métrica. Para Hayes (1995), há basicamente três tipos de pés: o iambo, o troqueu mórico e o troqueu silábico. Esses pés, parametricamente sistematizados, seriam suficientes para captar a estrutura rítmica das línguas.

O iambo pode conter duas sílabas no máximo, desde que a mais forte esteja à direita. Se o pé for dissilábico, o membro esquerdo deve ser uma sílaba leve. No troqueu mórico, duas sílabas leves equivalem a uma sílaba pesada. Este troqueu leva em conta o peso silábico e é constituído por um pé com duas moras. Por fim, o troqueu silábico é um pé que contém duas sílabas, das quais a mais proeminente é a da esquerda. Vejamos, em (1), a representação de cada um dos tipos de pé propostos por Hayes (1995, p. 63-69):

(1)

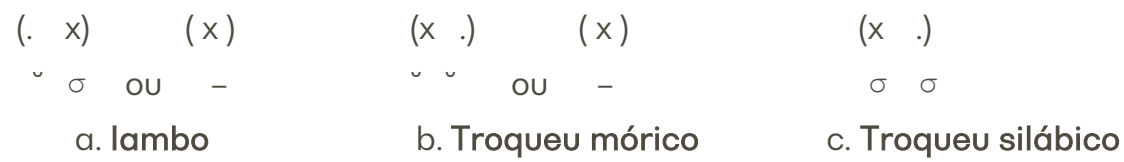

Apesar da existência desses três tipos de pé, nem todas as línguas permitem a existência de pés "degenerados", que são definidos por Hayes (1995, p. 86) como os menores pés 
logicamente possíveis. Em (2), apresentamos a formulação preliminar de pé degenerado feita pelo autor:

(2)

a. lambo

$(x)$ b. Troqueu mórico

$(\mathrm{x})$

\section{c. Troqueu silábico}

$(x)$

Se os pés degenerados não forem permitidos, muitas palavras terão sílabas deixadas fora do pé. Nesse sentido, a proposta de Hayes (1995, p. 87) é a de que as línguas proíbem os pés degenerados em níveis diferentes, pois nas línguas que não admitem esse tipo de pé, a proibição é forte. Nas que o permitem, quando é dominado por outra marca de grade, a proibição é fraca. A configuração de pé degenerado adotada por Hayes (1995, p. 102) contém um pé formado por uma sílaba leve, como exposto em (3):

\section{(3) Pé degenerado $(x)$}

Para Hayes (1995, p. 50), unidades menores que a sílaba não podem portar acento e "[...] as regras de construção do pé não podem dividir as sílabas". A Teoria Métrica Paramétrica, de Hayes (1995, p. 54-55), propõe que "[...] um sistema de regra é considerado como uma escolha particular de uma lista limitada de opções ou parâmetros". Dois desses parâmetros propostos na literatura para a escolha do tipo de pé seriam: a direção da escansão, que pode ser da esquerda para a direita ou da direita para a esquerda, e a iteratividade, cuja construção do pé pode ser iterativa (interpreta-se essa construção até onde der) ou não-iterativa (um único pé é construído e para-se nele).

Em relação à extrametricidade, Hayes (1995, p. 56-58) destaca quatro restrições para lidar com esse recurso, quais sejam: "o constituinte" - que determina quais elementos podem ser marcados como extramétricos -, "a perifericidade" - que exige que o elemento marcado como extramétrico esteja em uma das bordas (direita ou esquerda) do seu domínio -, "a marcação de borda" - que estabelece que a borda direita é a borda não marcada da extrametricidade - e "a não-exaustividade" - que impede que um domínio inteiro seja afetado pelas regras de extrametricidade.

Ao contrário do modelo métrico apresentado, que opera com regras, a Teoria da Otimidade vale-se de restrições universais que, por meio de ranqueamento, definem a gramática particular de uma língua. Os dois principais tipos de restrições com os quais a TO lida são as restrições de marcação e as restrições de fidelidade. Estas "[...] requerem que os outputs preservem as propriedades de suas formas (lexicais) básicas, exigindo algum tipo de 
similaridade entre o output e seu input" - como MAX (não apague); DEP (não insira) e $\operatorname{IDENT}(\mathrm{F})^{1}$ (os traços dos segmentos não devem ser mudados). Já as restrições de marcação exigem "[...] que as formas de output encontrem algum critério de boa formação estrutural" (KAGER, 1999, p. 9-10) - como PEAK (as sílabas devem conter uma vogal no núcleo) e ONSET (as sílabas devem conter ataque).

Para este trabalho, interessa-nos, especialmente, um conjunto de restrições que fazem parte de uma subteoria conhecida como Alinhamento Generalizado² (AG). De acordo com Russell (1997, p. 119), "ALINHE não é uma restrição, é um esquema para criar restrições". Esse esquema conta com duas categorias e duas bordas com as quais elas devem ser alinhadas:

(4) Esquema do Alinhamento Generalizado (RUSSELL, 1997, p. 119)

ALINHE (Categoria1, Borda1, Categoria 2 , Borda 2 )

Onde Categoria e Categoria $_{2}$ são categorias prosódicas ou gramaticais e Borda $\mathrm{e}_{1}$ Borda $_{2}$ podem ser esquerda ou direita.

Interpretação: para todos os casos da Categoria, há algum caso da Categoria 2 e a Borda $_{1}$ da Categoria 1 se alinha com a Borda 2 da Categoria ${ }_{2}$.

Com base nas premissas básicas da Fonologia Métrica e da Teoria da Otimidade, Magalhães (2004, 2010) analisa os não-verbos no português brasileiro. As restrições envolvidas para captar os fatos do padrão regular de acento dos nomes no português brasileiro (ex.: "vapor") são: PrWd-RIGHT (a borda direita de cada palavra prosódica é alinhada com a borda direita do cabeça de algum pé); GRID- $\mu$ HEAD (uma marca de grade (x) deve ocupar a mora cabeça de algum pé); PROJECT-SONORANT (toda soante pertencente a algum pé deve projetar uma posição na grade (por extensão, uma mora)); PARSE- $\sigma$ (toda sílaba deve ser escandida em algum pé) e *SHARED- $\mu$ (cada segmento na rima deve projetar sua própria mora) (MAGALHÃES, 2010, p. 122).

O padrão irregular dos nomes é representado pelas palavras paroxítonas terminadas em consoante obstruinte (ex.: "pires"); pelas paroxítonas terminadas em consoante soante (ex.: “líder”) e pelas proparoxítonas (ex.: "fôlego"). Segundo Magalhães (2010, p. 126-127), as restrições que atuam na gramática em favor do padrão irregular de acento dos nomes no PB são: STRESSFAITHFULNESS (o acento do input mantém-se na mesma posição no output (Hyde, 2001)); $\mu$-PROJECTION (toda mora deve projetar uma posição na grade); PROJECTOBSTRUENT (toda obstruinte pertencente a algum pé deve projetar uma marca de grade);

1 A letra "F" corresponde ao substantivo inglês feature, que, nesse contexto, significa traço.

2 Do inglês Generalized Alignment (McCARTHY; PRINCE, 1993b). 
*SHARED $\mu$-WEAK (cada segmento na rima deve projetar sua própria mora em sílaba não acentuada); PROJECT-SONORANT (toda soante pertencente a algum pé deve projetar uma posição na grade (por extensão uma mora)) e DEP- $\mu$ (proibido inserir mora).

Um diferencial dos trabalhos de Magalhães $(2004,2010)$ é não haver referência à extrametricidade. No caso de palavras como "fôlego", o acento é captado pela restrição STRESSFAITHFULNESS, que é altamente ranqueada. A hierarquia de restrições proposta por Magalhães (2010, p. 133) para o acento dos nomes no PB é a seguinte: DEP >> STRESSFAITH, RIGHTMOST, *SHARED $\mu-W E A K ~ \gg>$ PrWd-RIGHT, GRID- $\mu$ HEAD $\gg$ PARSE- $\sigma$, PROJOBST, $\mu$-PROJ > * SHARED- $\mu$.

Na próxima seção, apresentamos a caracterização métrica e as restrições que fazem parte da análise do acento verbal no PB.

\section{A CARACTERIZAÇÃO MÉTRICA DO ACENTO VERBAL NO PB E APRESENTAÇÃO DAS RESTRIÇÕES}

A acentuação dos verbos em português não pode ser generalizada por meio de uma única regra. Segundo Wetzels (2007), as regras de acentuação desta classe de palavras são:

(5) Regras básicas da acentuação verbal (WETZELS, 2007):

a. Tempos do passado: acentuar a vogal imediatamente seguinte à raiz.

fal] $\left.]_{\text {raiz }} \boldsymbol{d}\right]_{\text {temava }} \quad$ bat] raiz $\left.\boldsymbol{e}\right]_{\text {temaramos }}$ part] $]_{\text {raiz }}$ ] temaram

b. Tempos do futuro: acentuar a primeira sílaba do sufixo futuro.

bat $\left.]_{\text {raize }}\right]_{\text {temar }}$ i $\quad$ part $\left.]_{\text {raizi }}\right]_{\text {temar }}$ ria

c. Tempos do presente: na primeira e segunda pessoas do plural, acentuar a vogal temática; nos demais contextos, acentuar a última vogal da raiz. Em síntese, acentuar a penúltima sílaba.

bat $]_{\text {raize }} \quad$ fall $]_{\text {raiz }}$ amos

d. Infinitivo, gerúndio e particípio: acentuar a vogal temática.

fall $\left.]_{\text {raiz }}\right]_{\text {temar }}$ bat] raiz $\boldsymbol{e}$ temando part] $\left.]_{\text {raiz }}\right]_{\text {temado }}$

Para Bisol (1994), as sílabas em português são estruturadas em pés métricos binários de cabeça à esquerda, representados como ( ${ }^{*}$.), em que o asterisco indica a sílaba dominante e o ponto a sílaba dominada. No modelo métrico de Hayes (1995), a proposta da 
autora é representada por um troqueu, os pés são construídos da direita para a esquerda, não-iterativamente e a extrametricidade pode atingir segmentos ou sílabas por meio de uma regra específica. Os parâmetros em (6), a seguir, que foram baseados na perspectiva da Teoria Métrica Paramétrica (HAYES, 1995) e na proposta deste estudo, seriam suficientes para captar os fatos referentes ao acento primário dos verbos no PB:

(6) a. Construção do pé: Forme um troqueu silábico não-iterativo da direita para a esquerda.

Pés degenerados são permitidos apenas na posição forte, quando o pé canônico não puder ser formado (proibição fraca).

b. Extrametricidade: a desinência de plural na $1^{\text {a }}$ e $2^{a}$ pessoas do plural dos verbos dos tempos do imperfeito, do mais-que-perfeito e do futuro do pretérito do indicativo. Nos casos restantes, a consoante final com status de desinência, ou seja, Nou $S$.

c. Regra Final: à direita.

Para exemplificar a configuração métrica do acento verbal no PB, em (7), a seguir, nos pautamos nos tempos verbais descritos em Pereira (1999) e em Wetzels (2007). Essa configuração foi baseada em Bisol $(1992,1994)$ e nos parâmetros em (6):

(7) Representação métrica do acento primário dos verbos no PB

a) Presente do Indicativo: $(x$.) ba.to

b) Pretérito perfeito do indicativo: $\quad(x)$

par.ti

c) Pretérito imperfeito do indicativo: $(x \quad$.)

fa.lá.va.<mos>

d) Futuro do presente do indicativo: $\quad(x$.

par.ti.re.i<s>

e) Futuro do presente do subjuntivo: $\quad$ (x.)

par.ti.ri. $a<m>$

Interpretada pelo modelo de Hayes (1995), a representação métrica, em (7), permitiunos tecer as seguintes generalizações: 
(8)

- O pé básico é o troqueu silábico;

- Os pés são maximamente dissilábicos, ou seja, podem ter uma ou duas sílabas;

- Pés degenerados são permitidos;

- Cada tempo verbal tem a sua acentuação própria;

- O fato de uma sílaba ser de rima ramificada não implica que ela receberá acento;

- A extrametricidade pode atingir a sílaba final ou a consoante final, no caso, $\mathrm{N}$ ou S, dependendo da pessoa do verbo e do tempo verbal;

- O acento recai na vogal da raiz, na vogal temática (que, neste trabalho, denomina também a primeira vogal imediatamente seguinte à vogal da raiz) ou na vogal do sufixo flexional, conforme o tempo verbal e, em alguns casos, a pessoa do verbo;

- O acento faz referência explícita ao contexto morfológico.

Desse modo, em uma análise amparada teoricamente pela TO, as restrições envolvidas são sugeridas através de generalizações descritivas, como as que apresentamos em (8). Isso acontece porque são os fatos da língua que sugerem quais restrições farão parte da análise.

Assim, em (9), apresentamos as nove restrições consideradas relevantes para a análise do acento verbal no PB:

(9) TROQUEU: os pés têm proeminência inicial.

FOOTBINARITY (FTBIN): os pés são binários no nível da sílaba.

PARSE- $\sigma:$ todas as sílabas devem ser escandidas em pés.

RIGHTMOST: Alinhe (PrWd, R, Hd(PrWd), R): alinhe a borda direita da palavra prosódica com a borda direita do pé cabeça (o pé mais proeminente da palavra está na borda direita).

ALINHE-SUFIXO(Futuro): Alinhe (Afixo, Borda Esquerda, Palavra Prosódica, Borda Direita): alinhe a borda esquerda de cada sufixo com a borda direita de uma palavra prosódica.

SNONFINALITY ou NONFIN (Pé-GM, Sílaba, PrWd): Cada marca de grade no nível do pé tem uma categoria descendente silábica no domínio da palavra prosódica.

PrWd-RIGHT ou Alinhe (PrWd, R, Ft-Hd, R): a borda direita de cada palavra prosódica é alinhada com a borda direita do cabeça de algum pé.

ALINHE-TEMA: ALINHE (PrWd, D, Tema (PrWd), D): Alinhe a borda direita da palavra prosódica com a borda direita do tema verbal. 
*FINALIDADE(Presente): Proibido acento final nos verbos do presente (indicativo e subjuntivo).

A seguir, apresentamos a análise do acento verbal no PB.

\section{O ACENTO VERBAL NO PB: ANÁLISE E PROPOSTA DE UMA GRAMÁTICA DE RESTRIÇÕES}

Nesta seção, apresentamos a análise do acento dos verbos no PB e, em seguida, propomos uma gramática de restrições e sua respectiva hierarquia. A base para cumprirmos esta análise são os parâmetros em (6), referentes à construção do pé, à extrametricidade, que atinge tempos verbais específicos, e à Regra Final. Todos os exemplos que aparecem nos tableaux são de Wetzels (2007).

Em relação ao ranqueamento das restrições, Lee (2007, p. 143) já havia referido que "a dominância da morfologia sobre a fonologia significa que a morfologia exerce papel crucial na determinação do acento". Nos termos da TO, as restrições morfológicas dominam as restrições fonológicas. Neste trabalho, as restrições morfológicas, que são representadas por restrições de alinhamento, são ranqueadas mais alto do que as restrições fonológicas. As restrições morfológicas de alinhamento a que nos referimos são três, quais sejam: ALINHE-TEMA, ALINHE-SUFIXO(Futuro) e *FINALIDADE(Presente).

Sem estas restrições não seria possível construir uma análise capaz de captar o acento verbal, uma vez que uma única restrição morfológica não consegue captar a acentuação de todos os tempos verbais. Por isso, a exigência de ALINHE-TEMA é que a vogal temática seja acentuada nos tempos do passado, no infinitivo, no particípio, no gerúndio e no futuro do subjuntivo. Já ALINHE-SUFIXO(Futuro) requer que a vogal inicial do sufixo futuro seja acentuada e, por fim, *FINALIDADE(Presente) exige que a sílaba final seja átona nos tempos do presente.

Vejamos nos tableaux a seguir como essas restrições atuam em conjunto com as restrições fonológicas para garantir que cada tempo verbal seja acentuado corretamente. 


\begin{tabular}{|c|c|c|c|c|c|c|c|}
\hline$/ f a l+e+i /$ & $\begin{array}{l}\text { ALINHE- } \\
\text { TEMA }\end{array}$ & $\begin{array}{l}\text { RIGHT } \\
\text { MOST }\end{array}$ & TROQUEU & $\begin{array}{c}\text { SNON } \\
\text { FINALITY }\end{array}$ & $\begin{array}{l}\text { PrWd- } \\
\text { RIGHT }\end{array}$ & FTBIN & PARSE- $\sigma$ \\
\hline $\begin{array}{c}(x) \\
\text { a. fa.lei }\end{array}$ & & & & * & & * & * \\
\hline $\begin{array}{c}(. x) \\
\text { b. fa.lei }\end{array}$ & & & *! & * & & & \\
\hline $\begin{array}{c}(x .) \\
\text { c. fa.lei }\end{array}$ & ${ }^{*} !$ & & & * & * & & \\
\hline $\begin{array}{c}(x) \\
\text { d. fa.lei }\end{array}$ & *! & * & & & * & * & * \\
\hline
\end{tabular}

Tableav 1. Verbo "falei" (/fall]raiz $\boldsymbol{\theta}$ temai/)

Os candidatos (1c) e (1d) são os primeiros a serem eliminados, porque não acentuam a vogal temática e, assim, não satisfazem a exigência da restrição ALINHE-TEMA, a mais alta da hierarquia. O candidato (1d) ainda viola as restrições RIGHTMOST, por não construir um pé na borda direita, e PrWd-RIGHT, pelo fato de o cabeça do pé não estar alinhado com essa borda. Esse candidato também não satisfaz FTBIN e PARSE- $\sigma$, porque o pé construído não é binário e uma sílaba não é escandida. Já o candidato (1c), por construir um troqueu canônico, viola tanto SNONFINALITY quanto PrWd-RIGHT. Quase todas as restrições em jogo são satisfeitas pelo candidato (1b), mas a sua eliminação acontece ao violar TROQUEU, visto que constrói um pé iâmbico. Apesar de violar três restrições - SNONFINALITY, FTBIN e PARSE- $\sigma-$, o candidato (1a) acentua a vogal temática e constrói um pé trocaico na borda direita, o que satisfaz as três restrições mais altas e resulta em sua vitória.

Exemplos como o verbo "falei", da primeira pessoa do singular do pretérito perfeito do indicativo da primeira conjugação, não aparecem na análise de Lee (2007). Já Massini-Cagliari (2005, p. 211) afirma que a mesma hierarquia de restrições proposta para os verbos no infinitivo também vale para verbos como "falei" "[...] e para a $3^{\text {a }}$ pessoa do singular do mesmo tempo/modo, em todas as conjugações (ex. cantou, defendeu, partiu), que formam oxítonas terminadas em ditongos". O fato de que todos esses verbos são acentuados na vogal temática também poderia justificar a existência de uma única hierarquia capaz de explicar a acentuação nesses casos, uma vez que o acento verbal leva em conta o condicionamento morfológico, independentemente da constituição da sílaba.

No que se refere aos verbos dos tempos do imperfeito, a regra proposta por Bisol (1994) torna a sílaba "mos" invisível para as regras de acento nos verbos. O tableau 2 representa essas formas verbais tendo como exemplo o verbo "faláramos", que é acentuado na 
antepenúltima sílaba. Para dar conta da invisibilidade da última sílaba, a restrição SNONFINALITY exige que a sílaba final não seja escandida.

\begin{tabular}{|c|c|c|c|c|c|c|c|}
\hline /fal+a+ramos/ & $\begin{array}{l}\text { ALINHE- } \\
\text { TEMA }\end{array}$ & $\begin{array}{l}\text { RIGHT } \\
\text { MOST }\end{array}$ & TROQUEU & $\begin{array}{c}\text { SNON } \\
\text { FINALITY }\end{array}$ & PrWd-RIGHT & FTBIN & $\begin{array}{l}\text { PAR } \\
\text { SE- } \sigma\end{array}$ \\
\hline $\begin{array}{c}(x .) \\
\text { a. fa.la.ra.mos }\end{array}$ & & * & & & ** & & ** \\
\hline $\begin{array}{c}(x \quad) \\
\text { b. fa.la.ra.mos }\end{array}$ & ${ }^{*} !$ & & & * & * & & ** \\
\hline $\begin{array}{l}(. x) \\
\text { c. fa.la.ra.mos }\end{array}$ & & **! & * & & ** & & ** \\
\hline $\begin{array}{r}(\mathrm{x}) \\
\text { d. fa.la.ra.mos }\end{array}$ & *! & & & * & & * & *** \\
\hline
\end{tabular}

Tableau 2. Verbo "faláramos" (/fal] [raiza]temaramos/)

A violação de ALINHE-TEMA gera a eliminação imediata dos candidatos (2b) e (2d), visto que ambos não acentuam a vogal temática. O candidato (2b) também viola SNONFINALITY, PrWd-RIGHT e PARSE- $\sigma$, pois constrói um pé trocaico canônico na borda direita e não escande duas sílabas. O candidato (2d) também viola SNONFINALITY e PARSE- $\sigma$, e, por construir um pé monossilábico, viola a restrição FTBIN. Quase todas as restrições da hierarquia não são satisfeitas pelo candidato (2c), mas a sua eliminação acontece devido à violação de duas das três restrições mais altas, ou seja, RIGHTMOST e TROQUEU, uma vez que esse candidato constrói um pé iâmbico a duas sílabas de distância da borda direita. Embora viole RIGHTMOST, o candidato (2a) é o vencedor, porque satisfaz TROQUEU, ALINHE-TEMA e SNONFINALITY. Esse candidato não escande a sílaba final e constrói um pé trocaico, cujo cabeça é a vogal temática.

O tableav 3 exemplifica os verbos da segunda conjugação e, ao lado do verbo "bate", "bati" representa um caso de contraste acentual. Vejamos, a seguir, a análise do verbo "bati", que pertence a primeira pessoa do singular do pretérito perfeito do indicativo. 


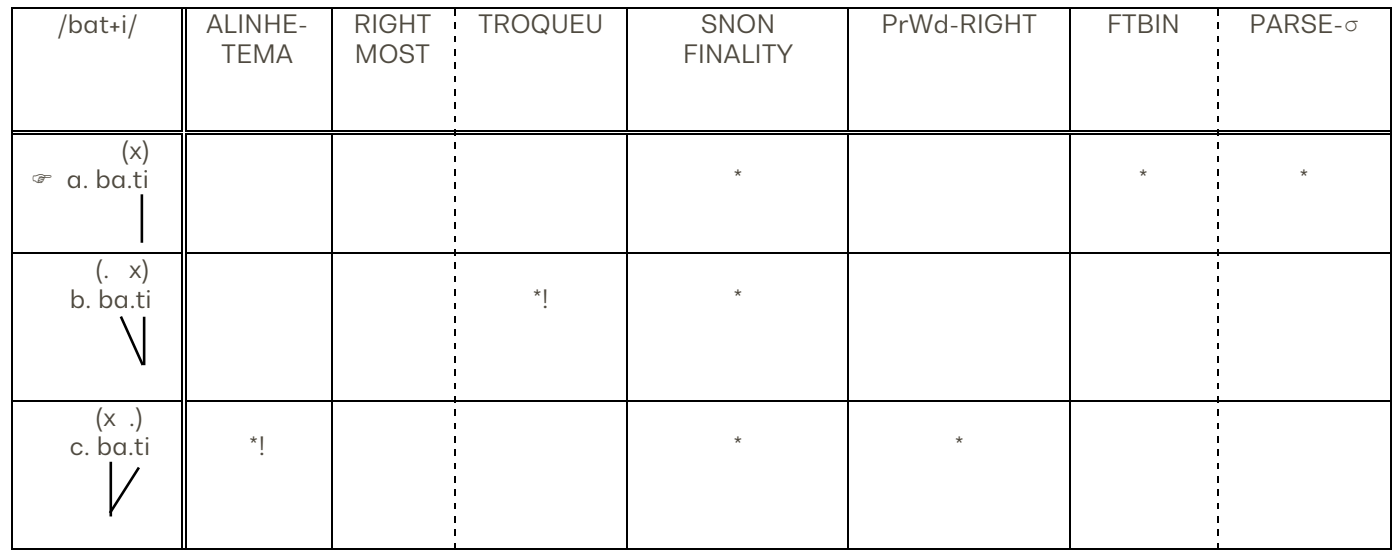

Tableav 3. Verbo "bati" (/bat] [raiz]tema/)

No tableav3, todos os candidatos satisfazem a restrição RIGHTMOST e violam SNONFINALITY. O candidato (3c) constrói um pé trocaico e não viola a maioria das restrições da hierarquia, mas, por não acentuar a vogal temática, viola ALINHE-TEMA, a restrição mais alta, e é eliminado. $O$ candidato (3b) satisfaz a exigência desta restrição, porém, constrói um pé iâmbico na borda direita, o que viola TROQUEU e causa a eliminação desse candidato. O candidato (3a) acentua a vogal temática e constrói um pé trocaico na borda direita, o que satisfaz as três restrições mais altas e faz com que esse candidato seja o vencedor.

Para Lee (1994, p. 40), verbos acentuados na última sílaba são casos marcados para o acento verbal, têm cabeça à direita e são representados na estrutura métrica por um iambo. Tendo como exemplo o verbo "perdi", Lee (2007, p. 139) mostra o domínio da restrição $\mathrm{PU}^{3}$ sobre TROQUEU para gerar o candidato ótimo "(perdí)". Para analisar verbos como "parti" e "partia", Massini-Cagliari (2005, p. 211-212), propõe as restrições *HIATO e MAX(VT, des.)-Pret.. ${ }^{4}$ Essas restrições são as mais altas da hierarquia e "[...] a forma ótima escolhida corresponde àquela que preserva as moras provenientes de ambas as vogais". Os respectivos candidatos vencedores para os verbos citados são "par.(ti:)" e "par.(ti:.a)".

Em casos como "bate" e "bati", "partira" e "partirá", as restrições de alinhamento exercem um papel fundamental para gerar o candidato correto como o vencedor, de acordo com cada tempo verbal. Por isso, a interface entre a morfologia e a fonologia é mais evidente em verbos que apresentam contraste acentual. O tableau 4 contém a análise do verbo "bate", da terceira pessoa do singular do presente do indicativo, cujo contraste foi apresentado no tableav anterior com "bati".

3 Uniformidade Paradigmática, em português. Esta restrição exige que a vogal temática seja acentuada nas formas verbais do tempo passado

4 Segundo Massini-Cagliari (2005, p. 212), as formulações dessas restrições são as seguintes: *HIATO: Hiatos entre VT e V(desinência), nas formas "do pretérito", são proibidos.

MAX(VT, des.)-Pret.: Maximize VT e V(desinência) nos verbos do "pretérito". (= Não apague VT e V(desinência) nos verbos do "pretérito".) 


\begin{tabular}{|c|c|c|c|c|c|c|c|}
\hline$/$ bat+e/ & ${ }^{{ }^{*} \mathrm{FIN}(\mathrm{Pr})}$ & $\begin{array}{l}\text { RIGHT } \\
\text { MOST }\end{array}$ & TROQUEU & $\begin{array}{c}\text { SNON } \\
\text { FINALITY }\end{array}$ & PrWd-RIGHT & FTBIN & PARSE- $\sigma$ \\
\hline $\begin{array}{c}(x \quad) \\
\text { a. ba.te } \\
\text { be }\end{array}$ & & & & $*$ & * & & \\
\hline 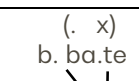 & ${ }^{* !}$ & & * & * & & & \\
\hline $\begin{array}{c}(x) \\
\text { c. ba.te } \\
\mid\end{array}$ & *! & & & * & & * & * \\
\hline
\end{tabular}

Tableav 4. Verbo "bate" (/bat] raize/)

Como os três candidatos do tableav 4 escandem a sílaba final, todos violam SNONFINALITY. A restrição *FIN(Pr), ranqueada mais alto, garante a atonicidade da sílaba final nos verbos dos tempos do presente e só é satisfeita pelo candidato (4a). Esse candidato constrói um pé trocaico padrão e é o vencedor, uma vez que esse tipo de pé satisfaz as três restrições mais altas. Os candidatos (4b) e (4c) são eliminados, porque violam *FIN(Pr). Além da restrição mais alta, o candidato (4b) constrói um iambo e também viola TROQUEU. $\mathrm{O}$ candidato (4c) constrói um pé monossilábico e deixa uma sílaba fora do pé, o que não satisfaz FTBIN e PARSE- $\sigma$, as duas restrições mais baixas da hierarquia.

A hierarquia proposta no tableav 4 também capta o acento da segunda pessoa do singular do presente do indicativo, como em "falas" e "batas". A existência do tableau 5, a seguir, se justifica para mostrarmos que a estrutura silábica não interfere na atribuição do acento verbal, pois o verbo terminar em consoante (no caso, $S$ ) não faz diferença para a vitória do candidato correto.

\begin{tabular}{|c|c|c|c|c|c|c|c|}
\hline /fal+as/ & ${ }^{\star} \mathrm{FIN}(\mathrm{Pr})$ & $\begin{array}{l}\text { RIGHT } \\
\text { MOST }\end{array}$ & TROQUEU & $\begin{array}{l}\text { SNON } \\
\text { FINALITY }\end{array}$ & $\begin{array}{l}\text { PrWd- } \\
\text { RIGHT }\end{array}$ & FTBIN & $\begin{array}{l}\text { PARSE- } \\
\sigma\end{array}$ \\
\hline $\begin{array}{c}(x \quad) \\
\text { a. fa.las }\end{array}$ & & & & * & * & & \\
\hline $\begin{array}{c}(. \quad x) \\
\text { b. fa.las }\end{array}$ & ${ }^{*} !$ & & * & * & & & \\
\hline $\begin{array}{c}(x) \\
\text { c. fa.las }\end{array}$ & *! & & & * & & * & * \\
\hline
\end{tabular}

Tableau 5. Verbo "falas" (/fal] raizas/) 
Todos os candidatos do tableau 5 constroem um pé na borda direita e, assim, escandem a sílaba final. Por isso, os três candidados satisfazem RIGHTMOST e violam SNONFINALITY. Os candidatos (5b) e (5c) são eliminados por violarem a restrição *FIN(Pr), a mais alta da hierarquia, visto que a sílaba final é a portadora do acento primário nos dois casos. O candidato (5c) constrói um pé degenerado e deixa uma sílaba sem escandir, o que não satisfaz as exigências de FTBIN e PARSE- $\sigma$. Essas duas restrições não são violadas pelo candidato (5b), mas, ao construir um iambo, esse candidato viola TROQUEU e é eliminado. Como o cabeça do pé não está na borda direita, o candidato $(5 a)$ viola PrWd-RIGHT, mas a construção de um pé troqueu canônico nesta borda satisfaz as restrições mais altas e o elege como o vencedor.

Em relação aos verbos dos tempos do futuro, neste trabalho, seguindo as propostas de Bisol (1992, 1994), Massini-Cagliari (2006) e Borges (2008), consideramos esses verbos como sendo palavras compostas, que, na escrita, tornam-se palavras aglutinadas, devido à atuação da Regra Final. Desse modo, permanece apenas o acento da borda direita, que é o acento principal. Na TO, as restrições capazes de explicar esses fatos são ALINHE-SUFIXO(F) e RIGHTMOST. Vejamos, no tableav 6, a análise para o acento dos verbos da primeira pessoa do plural do futuro do presente, exemplificados pelo verbo "falaremos".

\begin{tabular}{|c|c|c|c|c|c|c|c|}
\hline /fal+a+remos/ & $\begin{array}{l}\text { ALINHE- } \\
\text { SUF(F) }\end{array}$ & $\begin{array}{l}\text { RIGHT } \\
\text { MOST }\end{array}$ & TROQUEU & $\begin{array}{c}\text { SNON } \\
\text { FINALITY }\end{array}$ & $\begin{array}{l}\text { PrWd- } \\
\text { RIGHT }\end{array}$ & FTBIN & PARSE- $\sigma$ \\
\hline $\begin{array}{c}(x \quad) \\
\text { a. fa.la.re.mos }\end{array}$ & & & & * & * & & ** \\
\hline b. fa.la.re.mos & & ${ }^{*} !$ & * & & * & & ** \\
\hline $\begin{array}{l}(x .) \\
\text { c. fa.la.re.mos }\end{array}$ & *! & * & & & ** & & ** \\
\hline $\begin{array}{c}(x) \\
\text { d. fa.la.re.mos }\end{array}$ & ${ }^{*} !$ & & & * & & * & 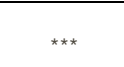 \\
\hline
\end{tabular}

Tableau 6. Verbo "falaremos" (/fall]raiza]temaremos/)

Todos os candidatos do tableav 6 deixam alguma sílaba sem escandir e, por isso, violam PARSE- $\sigma$. Por não acentuarem a vogal inicial do sufixo flexional, os candidatos (6d) e (6c) violam ALINHE-SUF $(F)$ e deixam a competição. O pé degenerado construído na borda direita pelo candidato (6d) resulta em outras cinco violações, uma para SNONFINALITY, uma para FTBIN e três para PARSE- $\sigma$. O candidato (6c) satisfaz TROQUEU e SNONFINALITY, 
já que a sílaba final não é escandida, mas comete muitas violações, incluindo uma para RIGHTMOST. Tanto o candidato (6a) quanto o (6b) acentuam a primeira vogal da desinência de futuro, porém, (6b) constrói um iambo fora da borda direita e, assim, viola RIGHTMOST e TROQUEU. Esse candidato é eliminado, deixando a vitória para (6a), que não viola nenhuma das restrições mais altas.

Para cumprir o principal objetivo deste estudo, a análise que desenvolvemos nos permitiu gerar, a seguir, a gramática de restrições e a hierarquia de restrições do acento dos verbos no português brasileiro.

\section{- Gramática de restrições proposta para o acento verbal no PB:}

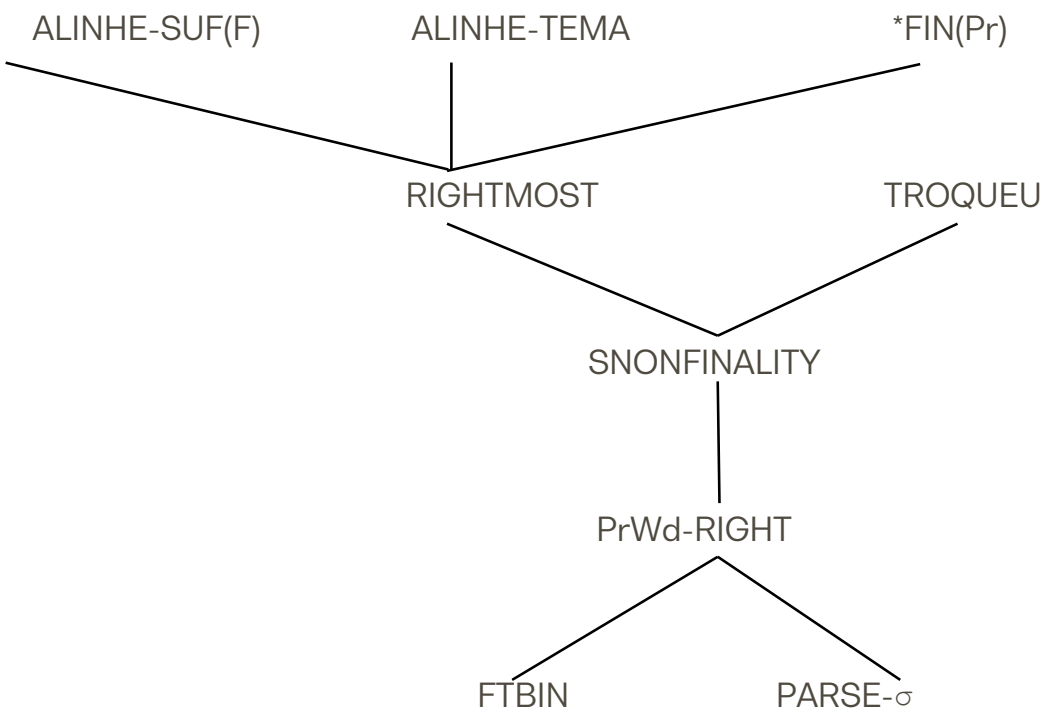

- Hierarquia de restrições proposta para o acento verbal no PB:

ALINHE-SUF(F), ALINHE-TEMA, *FIN(Pr) >> RIGHTMOST, TROQUEU >> SNONFINALITY >> PrWd-RIGHT > FTBIN, PARSE- $\sigma$.

O ranqueamento das restrições morfológicas ALINHE-SUFIXO(Futuro), ALINHE-TEMA e *FINALIDADE(Presente) no topo da gramática e no começo da hierarquia mostra a importância do condicionamento morfológico para atribuir o acento aos verbos e, assim, garantir que o paradigma de cada tempo verbal seja respeitado. As restrições RIGHTMOST e TROQUEU também são altamente ranqueadas e atuam juntas para que um pé trocaico seja construído na borda direita da palavra, que é o padrão da maioria dos verbos. Em conflito com estas duas restrições está SNONFINALITY, cuja exigência é de que a sílaba final não seja escandida. A restrição PrWd-RIGHT, que requer que o cabeça do pé esteja na borda 
direita da palavra prosódica, aparece logo em seguida. As restrições mais baixas são FTBIN e PARSE- $\sigma$, pois nem sempre o melhor candidato constrói um pé binário e a escansão das sílabas é não-iterativa, ou seja, um único pé é construído e para-se nele.

Se comparada com a hierarquia proposta neste trabalho, na que foi proposta por Magalhães (2010) para os não-verbos do PB (DEP >> STRESSFAITH, RIGHTMOST, *SHARED $\mu$ WEAK > PrWd-RIGHT, GRID- $\mu$ HEAD $>>$ PARSE- $\sigma$, PROJOBST, $\mu$-PROJ > * SHARED- $\mu$ ), podemos destacar o predomínio das restrições que se referem à mora e o alto ranqueamento da restrição STRESSFAITH para garantir que o acento do input seja preservado no output, uma vez que o autor não faz referência à extrametricidade em sua análise. Das restrições que fazem parte da hierarquia do acento dos não-verbos, apenas RIGHTMOST, PrWdRIGHT e PARSE- $\sigma$ estão na hierarquia referente ao acento verbal.

A seguir, apresentamos as considerações finais deste estudo.

\section{CONSIDERAÇÕES FINAIS}

O objeto de estudo deste trabalho foi o acento primário dos verbos no PB. A partir dos preceitos da Fonologia Métrica e da TO, construímos uma análise que nos permitiu propor uma gramática de restrições para o sistema verbal no português brasileiro. Em relação às hipóteses que formulamos no início deste estudo, com base nos resultados que obtivemos, todas se confirmaram. A análise revelou que a estrutura interna da sílaba não teve nenhuma relevância para o acento verbal. Como a maioria dos verbos do PB é paroxítona e o peso silábico não foi relevante para a atribuição do acento verbal, outra hipótese foi confirmada, a de que o troqueu silábico é o pé canônico dessa categoria lexical.

A interação entre a morfologia e a fonologia fica evidente nos contrastes acentuais e é representada pela presença das restrições de alinhamento, no caso, ALINHE-SUFIXO(Futuro), ALINHE-TEMA e *FINALIDADE(Presente). Na análise, estas restrições estão no topo da hierarquia e mostraram-se essenciais para captar o acento verbal. Esse resultado é semeIhante ao obtido por Lee (2007, p. 143), uma vez que, segundo o autor, "[...] o acento do português resulta de interação entre as restrições prosódicas/rítmicas (TROQUEU, FTBIN, [...]) e as restrições morfológicas (como [...], PU, ALIGN) - Morfologia >> Fonologia”. Assim, mais duas hipóteses foram confirmadas: a que considera a importância das restrições de alinhamento para a análise e a que reconhece a relevância das informações morfológicas para o acento dos verbos.

Em relação às restrições que estão na gramática e na hierarquia que propomos, fizemos muitos testes até chegarmos ao resultado que apresentamos neste texto. Desde o princípio, pretendíamos construir a análise com o mínimo de restrições, alcançando o máximo de generalizações possível. No caso dos verbos, essa tarefa não é tão simples, devido 
às particularidades de cada tempo verbal. Para captar essas particularidades, em termos da TO, a interação entre morfologia e fonologia é demonstrada por meio de restrições morfológicas e fonológicas.

Ademais, buscávamos diferir esta análise da de trabalhos anteriores e bastante consistentes, mas que não tinham como foco apenas o acento verbal no PB. Lee (2007), por exemplo, analisou os acentos verbal e não-verbal e utilizou tanto a TO quanto a teoria de Hayes (1995). No entanto, as restrições apresentadas em sua análise diferem das que propomos, devido ao entendimento do autor sobre as formas verbais. Como mencionamos, Lee (2007) utiliza a restrição PU para captar o acento da vogal temática nos verbos do passado. Um verbo oxítono, como "perdi", seria uma exceção, um iambo. Neste trabalho, um verbo como esse é escandido com um pé troqueu não canônico, pois a teoria de Hayes (1995) permite esse tipo de pé e possibilita que verbos oxítonos não sejam tratados como exceção, mas como um pé trocaico. Esse entendimento simplifica a análise, uma vez que podemos ter um tipo de pé geral (troqueu) para todos os verbos.

Entretanto, algo que não fizemos neste trabalho - e que pode ser feito futuramente - foi pensar em uma aproximação entre a análise verbal e a não-verbal, algo que foi feito em Lee (2007). Como analisou as duas categorias, várias restrições (ex.: TROQUEU, FTBIN e PARSE) que apareceram em sua análise para os verbos estavam na análise dos não-verbos, o que não aconteceu na análise que construímos. Quando comparamos esta aos trabalhos de Magalhães (2004, 2010), há somente três restrições (RIGHTMOST, PrWd-RIGHT e PARSE- $\sigma$ ) em comum nas duas análises. Inicialmente, pretendíamos encontrar mais semelhanças entre as hierarquias, o que não aconteceu. Uma justificativa para esse resultado se sustenta na afirmação de Lee (2007) de que a morfologia pesa muito no acento verbal e este acento é insensível ao peso silábico, ao passo que o peso conta para o acento não-verbal.

Além das hipóteses, algumas perguntas também nortearam este estudo. Em relação ao papel das restrições morfológicas na análise do acento verbal, podemos afirmar que esse papel é fundamental, pois essas restrições demonstram a interface morfologia-fonologia e são altamente ranqueadas na hierarquia para garantir a posição correta do acento de acordo com cada tempo verbal. Outra função das restrições morfológicas é garantir que a localização do acento ocorra no contexto morfológico adequado ao tempo verbal analisado. Na comparação entre verbos e não-verbos, vimos que os verbos não seguem o paradigma dos não-verbos, porque cada tempo verbal tem a sua acentuação previsível e há morfemas flexionais que são átonos por natureza. Portanto, o verbo terminar em vogal não implica que o acento será paroxítono ou oxítono, se terminar em consoante, como nos não-verbos.

Quanto aos verbos proparoxítonos, queríamos saber se haveria algum tratamento especial para lidar com o acento verbal na antepenúltima sílaba, como ocorre com os não- 
verbos. A análise mostrou que, para dar conta da extrametricidade da sílaba final nos verbos, a exigência da restrição SNONFINALITY, ou seja, a de não escandir a sílaba final, deve ser respeitada e que esses verbos seguem os padrões de acentuação do tempo verbal ao qual pertencem.

Sobre como tratar as formas verbais dos tempos do futuro, se sintéticas (simples) ou analíticas (perifrásticas ou compostas), nos baseamos nos estudos de Massini-Cagliari (2006) e Borges (2008) para justificar a classificação dessas formas verbais como compostas. Com base na TO, a hierarquia de restrições que propusemos gera candidatos que preservam apenas um acento principal, de modo que vence aquele acentuado mais à direita, como requer a Regra Final. Essa regra torna formas literalmente compostas (por duas palavras e por dois acentos) em formas aglutinadas (com uma palavra e um único acento).

Por fim, o português brasileiro é ou não uma língua sensível ao peso silábico? Se levarmos em conta apenas o sistema verbal, conforme a análise que fizemos, o PB é insensível ao peso silábico. Entretanto, verbos e não-verbos diferem na atribuição do acento no que diz respeito ao peso. Como Magalhães $(2004,2010)$ mostrou em seus trabalhos, a constituição da sílaba é relevante para a atribuição do acento nos não-verbos. Já nos verbos, o peso da sílaba não interfere na atribuição do acento. Ainda há debates na literatura sobre o português brasileiro ser ou não sensível ao peso silábico, mas poderíamos pensar na possibilidade de o PB ser uma língua parcialmente sensível ao peso. Assim, teríamos um sistema misto, que não se encaixe em uma única classificação. Não tínhamos como interesse, neste artigo, nos debruçarmos sobre essa discussão, mas esse tema pode gerar assunto para um trabalho futuro.

\section{REFERÊNCIAS}

BISOL, Leda. O acento e o pé métrico binário. Cadernos de Estudos Linguísticos, n. 22, p. 69-80, 1992.

BISOL, Leda. O acento e o pé métrico binário. Letras de Hoje, v. 29, n. 4, p. 25-36, 1994.

BORGES, Poliana Rossi. Estrutura morfofonológica das formas futuras nas Cantigas de Santa Maria. $324 \mathrm{f}$. Tese de Doutorado (Linguística e Língua Portuguesa) - Programa de Pós-Graduação em Lingüística e Língua Portuguesa da Faculdade de Ciências e Letras, Universidade Estadual Paulista, Araraquara, 2008.

HAYES, Bruce. Metrical Stress Theory: Principles and Case Studies. Chicago: University of Chicago Press, 1995.

HYDE, Brett. Metrical and Prosodic Structure in Optimality Theory. 427f. PhD dissertation (Doctor of Philosophy Graduate Program in Linguistics) - Rutgers University, New Brunswick, New Jersey, 2001.

KAGER, René. Optimality Theory. Cambridge University Press, 1999.

LEE, Seung Hwa. A regra do acento do português: outra alternativa. Letras de Hoje, v. 29, n. 4, p. 37-42, 1994. 
LEE, Seung Hwa. O acento primário no português: uma análise unificada na teoria da otimalidade. In: ARAÚJO, Gabriel. Antunes de (Org.). O acento em português: abordagens fonológicas. São Paulo: Parábola Editorial, 2007, p. 121-143.

LIBERMAN, Mark. The Intonational System of English. Doctoral dissertation, Massachusetts Institute of Technology, Cambridge, 1975.

LIBERMAN, Mark; PRINCE, Alan. On stress and linguistic rhythm. Linguistic Inquiry, v. 8, p. 249-336, 1977.

MAGALHÃES, José S. de. O plano multidimensional do acento na teoria da Otimidade. $227 \mathrm{f}$. Tese (Doutorado em Letras) - Programa de Pós-Graduação em Letras, Pontifícia Universidade Católica do Rio Grande do Sul, Porto Alegre, 2004.

MAGALHÃES, José S. de. Acento. In: BISOL, Leda; SCHWINDT, Luiz Carlos. Teoria da Otimidade: Fonologia. Campinas: Pontes Editores, 2010, p. 93-134.

MASSINI-CAGLIARI, Gladis. A música na fala dos trovadores: Estudos de prosódia do Português Arcaico, a partir das cantigas profanas e religiosas. 348 f. Tese (Livre-Docência em Fonologia) - Faculdade de Ciências e Letras, Universidade Estadual Paulista, Campus de Araraquara, 2005.

MASSINI-CAGLIARI, Gladis. Sobre o status morfofonológico e prosódico das formas verbais de Futuro em Português Arcaico. Estudos da Língua $(\mathrm{gem})$. Questões de Fonética e Fonologia: uma Homenagem a Luiz Carlos Cagliari, n. 3, p. 91-104, 2006.

McCARTHY, John J.; PRINCE, Alan S. Generalized Alignment. In: BOOJ, G; VAN MARLE, J. Yearbook of Morphology, Dordrecht: Kluwer, 1993a, p. 79-153.

McCARTHY, John J.; PRINCE, Alan S. Prosodic Morphology l: constraint interaction and satisfaction. University of Massachusetts, Amherst and Rutgers University, 1993b.

PEREIRA, Maria Isabel Pires. O acento da palavra em português: uma análise métrica. $286 \mathrm{f}$. Dissertação (Doutoramento em Linguística Portuguesa) - Faculdade de Letras da Universidade de Coimbra, 1999.

PRINCE, Alan; SMOLENSKY, Paul. Optimality Theory: constraint interaction in generative grammar. Rutgers University and University of Colorado-Boulder, 1993.

RUSSELL, Kevin. Optimality Theory and Morphology. In: ARCHANGELI, Diana; LANGENDOEN, D. Terence. Optimality Theory: An Overview. Oxford: Blackwell, 1997, p. 102-133.

WETZELS, Leo. Primary Word Stress in Brazilian Portuguese and the Weight Parameter. Journal of Portuguese Linguistics, 2007, p. 9-58. 